\title{
Disseminated Histoplasmosis in HIV Positive Patients in Espírito Santo State, Brazil: A Clinical-Laboratory Study of 12 cases (1999-2001)
}

\author{
Janaina Aparecida Schineider Casotti, \\ Tânia Queiroz Reuter Motta, \\ Carlos Urbano Gonçalves Ferreira Júnior \\ and Crispim Cerutti Junior
}

\author{
Infectious Diseases Division, Hospital Universitário Cassiano \\ Antonio de Moraes, Vitória, ES, Brazil
}

\begin{abstract}
Twelve cases of histoplasmosis in HIV-infected patients were found in a retrospective analysis at the Hospital Universitário Cassiano Antônio de Moraes of the Universidade Federal do Espírito Santo (HUCAM), Vitória (ES), from June 1999 to May 2001. The frequency of histoplasmosis among HIV-positive patients was $\mathbf{2 . 1 \%}$ in the infectious diseases division of the hospital during this period. Histoplasmosis compromised mainly males (11/12), 27 to 44 years old, and residents of the metropolitan urban area (10/12). Alcohol abuse and tobacco smoking were described in 10 of the 12 patients. For all patients, this was the first opportunistic infection. Two of the 12 patients died; 10 patients had disseminated disease, one patient had an intestinal presentation and one had disease restricted to the lungs. The most frequent clinical manifestations were weight loss, fever, hepatomegaly and splenomegaly, coughing, abdominal pain, and diarrhea. Six of the 12 patients had skin lesions. Time of symptoms preceding the diagnosis varied from two months to one year. CD4 counts were below 200 cells $/ \mathrm{mm}^{3}$ in 9 of 10 patients. Diagnosis was made by histology in two thirds of the patients. The typical adult patient with HIV infection and histoplasmosis in our series was male, had a CD4 count below 200 cells $/ \mathrm{mm}^{3}$, had fever, weight loss, cough, abdominal pain and hepatomegaly in the last two months or more, had a high probability of alcohol and tobacco addiction, was having his first opportunistic infection, and had no identifiable environmental exposure risk.
\end{abstract}

Key Words: Histoplasmosis, AIDS, diagnosis, case series.

Histoplasmosis is a systemic fungal disease caused by Histoplasma capsulatum. This disease has worldwide distribution, but it is more prevalent in some regions of North and Central America [1-3]. Its real incidence is not known, since case reporting is not mandatory and depends on the decision of the physician. Prevalence data defining endemic areas comes from the results of past epidemiological surveys, based on the histoplasmin skin test [1-3].

Since the upsurge of the acquired immunodeficiency syndrome (AIDS), numerous opportunistic infections have been described in this subset of patients, including endemic mycosis [4,5]. Despite the universal availability of Highly Active AntiRetroviral Therapy (HAART) in the Brazilian national AIDS program, many patients present at first medical evaluation with severe immunosuppression and opportunistic infections. Histoplasmosis is one of the potential opportunistic infections. In order to help define clues for the early diagnosis of histoplasmosis, we evaluated the typical presentation of histoplasmosis and the demographic characteristics of patients presenting with histoplasmosis and AIDS in the Infectious

Received on 15 May 2006; revised 18 August 2006.

Address for correspondence: Dr. Crispim Cerutti Junior, Professor Assistente. Departamento de Ciências da Saúde do Centro Biomédico da Universidade Federal do Espírito Santo. Av. Marechal Campos, 1468, Maruípe, Vitória, ES. Zip code: 29.140-091. Phone: 273335-7225. Fax: 27-3335-7218. E-mail: fil.cris@terra.com.br.

The Brazilian Journal of Infectious Diseases 2006;10(5):327-330. (C) 2006 by The Brazilian Journal of Infectious Diseases and Contexto Publishing. All rights reserved.
Diseases Division of the Hospital Universitário Cassiano Antônio de Moraes, Universidade Federal do Espírito Santo (HUCAM).

We present our experience concerning clinical and laboratorial diagnosis of histoplasmosis in HIV-infected patients. Histoplasmosis is a possible opportunistic event and should be kept in mind.

\section{Material and Methods}

A retrospective review of all cases of histoplasmosis in the infectious disease ward of HUCAM was conducted. We analyzed clinical, laboratory and demographic data of patients from June 1999 to May 2001. The following variables were submitted to analysis: gender, place of birth, living place, illness duration, preceding admission, age, ethnicity, occupation, history of alcohol abuse and/or cigarette smoking, mortality rate, clinical manifestations, basic laboratory tests, CD4 count and HIV viral load.

Data acquired from records were complemented by histopathology and serology results, when available. Frequency of histoplasmosis was determined considering all the HIV-positive patients attending the HUCAM infectious diseases outpatient clinic from June 2, 1999 to May 23, 2001. Histoplasmosis diagnosis was based on at least one of three criteria: the finding of the fungus in tissue specimens, a positive serology result (immunodiffusion method) or a positive culture from a clinical specimen (brain-heart infusion broth). CD4 counts were determined by flow cytometry. HIV viral load was determined by a polymerase chain reaction method (F. Hoffmann-La Roche Ltd). 


\section{Results}

From May 1999 to June 2001, 12 patients with histoplasmosis were admitted, corresponding to $2.1 \%$ of the HIV-positive patients registered at the outpatient clinic during the same period $(n=571)$. Eleven of the 12 patients were males. Age varied from 27 to 44 years old. Five of the 12 patients were born in rural areas of Espírito Santo state. Ten patients were living in the capital (Vitória). Ten patients had always lived in Espirito Santo, one lived previously in Bahia state and another in Minas Gerais state. Race information was available for seven patients. Three of them were mixed, three white and one black. Information about occupation was available for eight patients: two farmers, two drivers, one metal worker, one market trader, one cook and one machine operator. The clinical manifestations are depicted in Table 1. Skin lesions were classified as crusty-erythematous, plaques, papules, papules with central depression or polymorphic. Lymphadenopathy was found in the following lymph systems: cervical, axillary, inguinal, supraclavicular and mesenteric.

Ten of the 12 patients had generalized disease, one had an intestinal form and one patient had disease restricted to the

Table 1. Clinical manifestations in 12 patients with AIDS and histoplasmosis

\begin{tabular}{lcc}
\hline & Number & \% of patients \\
\hline Weight loss & 11 & 91.7 \\
Fever & 10 & 83.3 \\
Hepatomegaly & 10 & 83.3 \\
Cough & 9 & 75 \\
Abdominal pain & 9 & 75 \\
Diarrhea & 7 & 58.4 \\
Splenomegaly & 7 & 58.4 \\
Skin lesions & 6 & 50 \\
Lymphadenopathy & 5 & 41.7 \\
Dyspnea & 4 & 33.4 \\
\hline
\end{tabular}

lungs. The mortality rate was two of 12 patients. Laboratory abnormalities are described in Table 2. All patients were treated with Amphotericin B on a daily basis $(1 \mathrm{mg} / \mathrm{kg}$ body weight daily, total dose of $35 \mathrm{mg} / \mathrm{kg}$ ), followed by a weekly maintenance dose of $1 \mathrm{mg} / \mathrm{kg}$ body weight.

The diagnosis was confirmed most frequently by histopathology (9/12); 5/12 were diagnosed from skin biopsies. Bone marrow culture was positive in three of the cases. Serology was positive in only one fourth of the patients (Table 3).

Time between symptom onset and hospital admission ranged from two months to one year (median: five months). HIV infection was acquired by sexual transmission in five of the 12 patients and by intravenous drugs injection in two of them. The transmission category was undetermined or not reported in five of the patients.
Table 2. Laboratory abnormalities in 12 patients with AIDS and histoplasmosis

\begin{tabular}{|c|c|c|}
\hline & Number & $\%$ of patients \\
\hline Anemia & 12 & 100 \\
\hline $\begin{array}{l}\text { Thrombocytopenia } \\
\left(<100.000 / \mathrm{mm}^{3}\right)\end{array}$ & 7 & 58.3 \\
\hline $\begin{array}{l}\text { Leukopenia } \\
\qquad \begin{array}{l}\left(<5,000 / \mathrm{mm}^{3}\right) \\
\left(<2,600 / \mathrm{mm}^{3}\right)\end{array}\end{array}$ & $\begin{array}{l}11 \\
10\end{array}$ & $\begin{array}{l}91.7 \\
83.3\end{array}$ \\
\hline \multicolumn{3}{|l|}{ Gama-GT } \\
\hline (>1000U/L) & 2 & 16.7 \\
\hline $\begin{array}{l}\quad(>100 \mathrm{U} / \mathrm{L}) \\
\text { Lactic dehydrogenase } \\
(>400 \mathrm{U} / \mathrm{L})\end{array}$ & $\begin{array}{l}8 \\
6\end{array}$ & $\begin{array}{l}66.7 \\
50\end{array}$ \\
\hline $\begin{array}{l}\text { Aminotransferases } \\
(>100 \mathrm{U} / \mathrm{L})\end{array}$ & 6 & 50 \\
\hline $\operatorname{Albumin}(<3 \mathrm{~g} / \mathrm{dL})$ & 5 & 41.7 \\
\hline $\begin{array}{l}\text { Activated partial } \\
\text { thromboplastin time }(>4\end{array}$ & $\begin{array}{l}4 \\
\text { seg) }\end{array}$ & 33.3 \\
\hline Prothrombin time $(<50 \%)$ & 3 & 25 \\
\hline Creatinine (>2mg/dL) & 2 & 16.7 \\
\hline
\end{tabular}

Alcohol abuse was detected in two thirds of the patients and cigarette smoking in 7/12.

Histoplasmosis was the first opportunistic infection in all of the 12 patients. Three patients had a diagnosis of AIDS based on CD4 cell counts below 350 cells $/ \mathrm{mm}^{3}$ before presentation with disseminated histoplasmosis. CD4 cell counts were available for 10 patients. They were $<200$ cells $/ \mathrm{mm}^{3}$ in nine of the 10 cases (range: 4 to 510 cells $/ \mathrm{mm}^{3}$ ). Viral load quantification was also available for 10 patients, with a median of 13,000 copies $/ \mathrm{mL}$ (ranging from undetectable to 3.5 million copies $/ \mathrm{mL}$ ).

\section{Discussion}

It is not uncommon for the presentation of HIV-positive patients to the physician to coincide with their first opportunistic infection. At the time of ward admission, the patient arrives very ill, with nonspecific signs and symptoms. Physicians need to determine the most probable diagnosis and prescribe the appropriate treatment. As a rule, the diagnoses frequently considered in these settings are tuberculosis, toxoplasmosis and Pneumocystis jiroveci pneumonia. Fungal infections are not considered initially, except if there are central nervous system symptoms, in which case cryptococcosis becomes a strong possibility. Nevertheless, histoplasmosis is an expected opportunistic event in those profoundly immunosuppressed patients, often associated with a CD4 count $<75 / \mathrm{mL}[6,7]$. In our study, CD4 counts below $200 / \mathrm{mL}$ in 9 of the 10 patients.

The first report of disseminated histoplasmosis in AIDS in Brazil was in 1986, published in 1988 [8]. The first case in our 
Table 3. Etiologic diagnosis of Histoplasma capsulatum infection in 12 patients with histoplasmosis and HIV infection at Hospital Universitário Cassiano Antonio de Morais from May 1999 to June 2001

\begin{tabular}{ccccccc}
\hline $\begin{array}{c}\text { Case } \\
\text { number }\end{array}$ & $\begin{array}{c}\text { Colon surgical } \\
\text { tissue speciemn } \\
\text { (histopathology) }\end{array}$ & $\begin{array}{c}\text { Skin specimen } \\
\text { (histopathology) }\end{array}$ & $\begin{array}{c}\text { Lymphnode } \\
\text { histopathology } \\
\text { (FNA) }\end{array}$ & Serology & $\begin{array}{c}\text { Bone marrow } \\
\text { culture }\end{array}$ & $\begin{array}{c}\text { BAL } \\
\text { culture }\end{array}$ \\
\hline 1 & + & - & - & neg & - & - \\
2 & + & - & + & neg & - & - \\
3 & - & - & + & + & - & - \\
4 & - & - & + & neg & - & + \\
5 & - & + & - & neg & + & - \\
6 & - & + & - & neg & - & - \\
7 & - & + & - & neg & - & - \\
8 & - & + & - & + & - & - \\
9 & - & - & - & neg & - & - \\
10 & - & - & - & + & + & - \\
11 & - & - & - & neg & + & - \\
12 & - & - & neg & + & - \\
\hline
\end{tabular}

FNA: fine needle aspiration. BAL: Bronchoalveolar lavage. Neg: negative; +: positive; -: data not available.

state was registered in 1987 (unpublished data from the Health State Secretary, coordination of sexually transmitted diseases and AIDS). Nowadays, this is a common opportunistic infection in Espírito Santo state, but its occurrence is not reported, which contributes to the low level of suspicion observed among physicians.

The frequency of disseminated histoplasmosis in our study was $2.1 \%$. This figure is similar to what was observed in other similar studies in endemic areas $(2-5 \%)[3,9,10]$, but less than findings from epidemic areas (such as greater than $25 \%$ in Indianapolis-USA) [3,9-11]. Cahn et al. found a higher frequency (8\%) in Brazil in 2000 [6], as did Segura et al. in Guatemala $(6.7 \%)$ [12] and Casariego et al. in Argentina $(3.6 \%)$ [13].

The mortality rate from histoplamosis is greater than $33 \%$ in immunosuppressed patients, nearly double that observed in immunocompetent patients (17\%) [6]. Disseminated histoplasmosis is progressively fatal if untreated [6]. In contrast, we found a low mortality rate of $2 / 12$ in our patients, similar to the figures reported by Hajjed et al. in 2001 (12\%) [14] and Karimi et al. in 2002 (19\% and 5\% to $13 \%$ for HIVinfected patients in Brazil and the United States, respectively) [15]. Possibly, this low mortality rate is a consequence of an exhaustive investigational work-up on each patient, making appropriate diagnosis and timely treatment possible.

Common signs and symptoms, fever and weight loss $[16,17]$ were found in 10 and 11 of the 12 patients, respectively, in our series. Respiratory symptoms, such as cough and dyspnea, usually reported in about $50 \%$ of patients in other series, were found in 9/12 and 4/12 of our patients, respectively. Other signs, such as hepatosplenomegaly and lymphadenopathy are described in about $25 \%$ of patients in other reports $[4,5,8,10,18-20]$. We found hepatomegaly in 10 of the 12 patients, splenomegaly in seven and lymphadenopathy in 5 of the 12 . These findings may have been more frequent in our institution because our patients arrived at the ward with a more advanced disease situation.

Anemia, reported in about $90 \%$ of cases, was found in all of our patients. Leukopenia and thrombocytopenia were described in $80 \%$ of the cases in other reports and were found in 11/12 and 7/12, respectively, in our study. Half of our patients had elevated liver enzymes levels, in agreement with the findings of Johnson et al. [7]. These authors reported biopsy and myeloculture as the most sensitive diagnostic procedures for histoplasmosis in AIDS, achieving 69\% positivity. Alves $[1,2]$ reported an even higher rate of positivity (79\%). In our series, the diagnosis was made more often by histopathology (positive results in 9/12 cases, five from skin biopsies), emphasizing the need for adequate examination of any possible source of tissue alterations in the diagnosis work-up.

Half of our patients had skin lesions; these were more frequently found in other Brazilian studies (Alves: $71.4 \%$, Rocha \& Severo: $68 \%$, Karimi et al.: 66\%) [1,2,15,18], but not in foreign studies (Johnson et al: 10.4\%, Wheat et al: 10\%) $[7,20]$. When submitted to biopsy procedures, skin lesions yielded a positive result in all of instances. Johnson et al. [7] reported positive results in $5 \%$ of the procedures and Alves in 79\% [1,2]. Apparently, skin lesions are more frequently found in Brazil in comparison to other countries, without an obvious explanation. Similarly, the diagnostic yield of the skin biopsies seems to be greater in Brazil than in most of the other countries where similar studies have been conducted.

Serology was not an important source of diagnosis in our study, as we found only $25 \%$ of histoplasmosis cases with the immunodiffusion method. Taking into account a foreign report (46\% to $79 \%$ positive rate) [21] and the study of Alves 
[1] (21\% positive rate in São Paulo, Brazil), the rate of diagnosis via serology in Brazil is below that found in other countries, suggesting that either Brazilian patients are more immunocompromised [22] or that the serology technique was less accurate. Recently, Leimann et al. also found a $57 \%$ positive rate among Brazilian patients [23].

In conclusion, our patients were all severely immunosuppressed and histoplasmosis was their first opportunistic infection. Most of them were males, presenting with fever, weight loss, coughing, abdominal pain or hepatosplenomegaly within the last two months. There were no epidemiologically-identifiable risk factors. Skin lesions were more common than in series from other countries, but the frequency was comparable to that observed in other Brazilian studies. Histopathology was the most important source of diagnosis and the contribution of serology was poor. The mortality rate was lower than previously reported.

\section{Acknowledgements}

We are grateful to the staff and technicians of the Departamento de Patologia do Centro de Ciências da Saúde and the HUCAM laboratory who processed and analyzed the samples collected from the patients.

\section{References}

1. Alves K.S. Histoplasmose disseminada e síndrome da imunodeficiência adquirida. Estudo clínico-laboratorial de 28 casos. M.Sc. thesis. Universidade de São Paulo, São Paulo, SP: 1996.

2. Alves K.S. Histoplasmose disseminada e síndrome da imunodeficiência adquirida. Estudo clínico-laboratorial de 28 casos. Rev Soc Bras Med Tropical 1998; 31:505.

3. Cano M.V.C, Hajjeh RA. The epidemiology of histoplasmosis: A review. Semin Respir Infect 2001;16:109-18.

4. Wheat J., Sarosi G., McKinsey D., et al. Practice guidelines for management of patients with histoplasmosis. Clin Infect Dis 2000;30:688-95.

5. Pietrobon D., Negro-Marquinez L., Kilstein J., et al. Disseminated histoplasmosis and AIDS in an Argentine hospital: clinical manifestations, diagnosis and treatment. Enferm Infecc Microbiol Clin 2004;22(3):156-9.

6. Cahn P., Belloso W.H., Murillo J., Prada-Trujillo G. Emerging and re-emerging diseases in Latin America. Infect Dis Clin North Am 2000; 14:185-209.

7. Johnson P.C., Khardori N., Najjar A.F., et al. Progressive Disseminated Histoplasmosis in Patients with Acquired Immunodeficiency Syndrome. Amer J Medicine 1988; $85: 152-8$.
8. Severo L.C., Oliveira F.M., Irion K., et al. Histoplasmosis in Rio Grande do Sul, Brazil: a 21-year experience. Rev Inst Med Trop S Paulo 2001;43:183-7.

9. Wheat J. Histoplasmosis. Clin Microbiol Rev 1995;8:146-59.

10. Wheat L.J., Chetchotisakd P., Williams B., et al. Factors Associated with Severe Manifestations of Histoplasmosis in AIDS. Clin Infect Dis 2000;30:977-81.

11. Wheat J. Histoplasmosis in the Acquired Immunodeficiency Syndrome. Curr Top Med Mycol 1996;7(1):7-18.

12. Segura L., Rojas M., Pelaez N., et al. Disseminated histoplasmosis and Human Immunodeficiency Vírus type 1 infection: Risk factors in Guatemala. Clin Infect Dis 1997;25:343-4.

13. Casariego Z., Rey Kelly G., Perez H., et al. Disseminated histoplasmosis with orofacial involvement in HIV-1-infected patients with AIDS: manifestations and treatment. Oral Dis 1997;3:184-7.

14. Hajjeh R.A., Pappas P.G., Henderson H., et al. Multicenter case-control study of risk factors for histoplasmosis in immunodeficiency virus-infected persons. Clinical Infectious Diseases 2001;32(8):1215-20.

15. Karimi K., Wheat L.J., Connolly P.A., et al. Differences in histoplasmosis in patients with acquired immunodeficiency syndrome in United States and Brazil. J Infec Diseases 2002;186(11):1655-60.

16. Gutierrez M.E., Canton A., Sosa N., et al. Disseminated histoplasmosis in patients with AIDS in Panama: a review of 104 cases. Clin Infect Dis 2005;40(8):1199-202.

17. Unis G., Oliveira F. de M., Severo L.C. Disseminated histoplasmosis in Rio Grande do Sul. Rev Soc Bras Med Trop 2004;37(6):463-8.

18. Rocha M.M., Severo L.C. Histoplasmose Disseminada em pacientes com Síndrome de Imunodeficiência Adquirida (SIDA). Estudo de 25 casos. Rev Inst Med Trop Sao Paulo 1994;36:167-70.

19. Sarosi G.A., Johnson P.C. Disseminated histoplasmosis in patients infected with Human Immunodeficiency Virus. Clin Infect Dis 1992;14(suppl. 1):60-7.

20. Wheat L.J., Connolly-Stringfield P.A., Baker R.L., et al. Disseminated histoplasmosis in the Acquired Immune Deficiency Syndrome: clinical findings, diagnosis and treatment, and review of the literature. Medicine 1990;69:361-74.

21. Morgan J., Cano M.V., Feikin D.R., et al. A large outbreak of histoplasmosis among American travelers associated with a hotel in Acapulco, Mexico, Spring 2001. Am J Trop Med Hyg 2003;69(6):663-9.

22. Tobon A. M., Agudelo C. A., Rosero, D. S., et al. Disseminated histoplasmosis: a comparative study between patients with acquired immunodeficiency syndrome and non-human immunodeficiency virus- infected individuals. Am J Trop Med Hyg 2005;73(3):576-82.

23. Leimann B.C., Pizzini C.V., Muniz M.M., et al. Histoplasmosis in a Brazilian Center: clinical forms and laboratory tests. Rev Iberoam Micol 2005;22:141-6. 